\title{
INFORMATION VALUE OF THE INTEREST RATE AND THE ZERO LOWER BOUND
}

\author{
Sang Seok Lee \\ Bilkent University
}

\begin{abstract}
Why is a zero lower bound episode long-lasting and disruptive? This paper proposes the interruption of information flow from the central bank's interest rate decision to the private sector as a channel by which the destabilizing effect of the zero lower bound constraint on the nominal interest rate is amplified. This mechanism is incorporated into the new Keynesian model by modifying its information structure. This paper shows that the information loss at the zero lower bound can increase (a) the duration of the zero lower bound episodes and (b) the size of deflation and output gap loss. The result in this paper demonstrates that enhanced information sharing by the central bank about the state of the economy can be effective at alleviating the cost of the zero lower bound.
\end{abstract}

Keywords: Interest Rate Zero Lower Bound, Asymmetric Information, Forward Guidance, Central Bank Transparency

\section{INTRODUCTION}

The recent economic crisis in the USA and the Eurozone demonstrated that the zero lower bound constraint on the nominal interest rate is not just a matter of theoretical curiosity: at the time of writing, the policy rates in these economies have remained close to zero for more than 7 years. Why has the zero lower bound episode been so long-lasting and disruptive? This paper proposes the interruption of information flow from the central bank's interest rate decision to the private sector $^{1}$ as one channel by which the destabilizing effect of the zero lower bound constraint is exacerbated. ${ }^{2}$ This mechanism is incorporated into the simple new Keynesian model by modifying its information structure. It will be shown that the information loss at the zero lower bound increases both the duration of the zero lower bound episodes and the size of deflation and output gap loss.

I would like to thank two anonymous reviewers, Guido Ascari, Paul Beaudry, Christopher Bowdler, Martin Ellison, Refet Gürkaynak, Tom Holden, Martina Jančoková, Burçin Kisacikoğlu, Thomas Lubik, Paul Luk, Richard Mash, Eric Mengus, Kubilay Öztürk, Cavit Pakel, Joe Pearlman, Amar Radia, Nicholas Woolley, Francesco Zanetti, and seminar participants at Bilkent, Central Bank of the Republic of Turkey, Oxford, SMYE, and T2M Conference for providing me with helpful comments. I also would like to thank Luca Guerrieri and Matteo Iacoviello for sharing their computer codes with me. Address correspondence to: Sang Seok Lee, Department of Economics, Bilkent University, 06800 Ankara, Turkey; e-mail: sang.lee@ bilkent.edu.tr. Phone: +90 3122902370. Fax: +90 3122665140 . 
The information value of the nominal interest rate for the private sector is built on the assumption that the central bank is better informed about the state of the economy than the private sector. Is this assumption justified? As documented by Romer and Romer (2000) and Sims (2002), the Fed's Greenbook forecasts of inflation tend to be more accurate than the private sector's forecasts. Among other reasons, this is possibly because the Fed has access to a much larger information set than the private sector. ${ }^{3}$ There is considerable empirical evidence in support of this notion [see Peek et al. (1999); Kuttner (2001); Gürkaynak et al. (2005), and Campbell et al. (2012)]. There is also evidence that this applies to other central banks as well [see Hubert (2015)]. How can this information advantage arise? In a recent interview with $\mathrm{BBC},{ }^{4}$ Spencer Dale, the then chief economist of the Bank of England, said the Bank did not possess any "special secrets" about the state of the economy. However, he also said

"What we do-and we do it an awful lot-as well as look at the aggregate data published by our statistical office, is we spend an awful lot of time going up and down the country speaking to businesses and learning first-hand what's going on."

This type of informal surveying can be a source of information advantages for central banks given that many of them are better-equipped than their private sector counterparts for carrying out such activity.

In this paper, the central bank uses an interest rate rule to set the nominal interest rate. As long as the nominal interest rate is outside the zero lower bound, the private sector can invert the interest rate rule and extract the missing piece of information which is informative about the state of the economy. However, this ceases to be the case at the zero lower bound because the interest rate rule is no longer invertible. This information problem at the zero lower bound complicates the signal extraction of the private sector and alters the dynamics of aggregate variables substantially through its effect on the expectation formation.

To illustrate this point, this paper first presents a model in which the only piece of information that the private sector has to retrieve from the nominal interest rate is the current demand shock, which is assumed to be known only to the central bank at the beginning of each time period. Among other reasons, ${ }^{5}$ this choice can be rationalized on the ground that the demand shock is something the central bank knows and cares more about than the private sector as it is related to the potential or natural level of output ${ }^{6}$ which is the key object in policy debates. The model uses this particular unobservable to demonstrate a point that is valid for any kind of information asymmetry that favors the central bank, for instance, the central bank's preference. ${ }^{7}$ The extension to the setting with more than one unobservable shock, which builds on the simple model above, is demonstrated with a model where both demand and supply shocks are present and subject to the information asymmetry and retrieval.

The methodological novelty in this paper is the application of mathematical tools of censored-data microeconometrics to a dynamic macroeconomic model. 
Specifically, the expected value of the current demand shock when the zero lower bound on the nominal interest rate is binding is derived using the inverse Mills ratio. This expected value has an analytical expression which is highly tractable as demonstrated below.

As mentioned above, it will be shown that the information problem at the zero lower bound makes (a) the output gap loss and the deflation larger and (b) the zero lower bound periods longer. Based on these observations, it will be established that the increased central bank transparency in the form of information revelation is especially beneficial at the zero lower bound as it alleviates the information problem associated with it. Thus, this paper contributes to the literature on the merits of central bank transparency [see Blinder (1998); Woodford (2005), and Blinder et al. (2008)] in addition to the literature on the zero lower bound [see Eggertsson and Woodford (2003) and Jung et al. (2005)]. Moreover, this paper also contributes to the literature on forward guidance [see Campbell et al. (2012) and references therein] which can be considered as a form of information revelation by which the central bank communicates the expected course of monetary policy to the private sector in order to manage the latter's expectations about the future. Rudebusch and Williams (2008) analyze the setting closest to the one here and rationalize the social value of publishing central bank's interest rate projections. However, this paper considers the zero lower bound problem additionally.

The zero lower bound literature has grown in volume substantially in the past few years. The seminal contributions in the zero lower bound literature are Jung et al. (2005) (which was motivated by Japan's experience in the past decades) and Eggertsson and Woodford (2003) (which was motivated by the USA's experience in the early 2000s as well as Japan's). Following in their footsteps, many researchers have written about various issues regarding the effect of the zero lower bound. A non-exhaustive list of contributions on the zero lower bound includes topics such as the optimal monetary policy [see Adam and Billi (2007); Nakov (2008), and Alstadheim (2016) (with the neoclassical Phillips curve); Billi (2017); Belgibayeva and Horvath (2017), and Ngo (2018)], fiscal policy [see Christiano et al. (2011); Woodford (2011); Aruoba and Schorfeide (2012), and Flotho (2015)], quantitative properties [see Fernández-Villaverde et al. (2015) and Nakata (2017)], open economy [see Bodenstein et al. (2009)], and exit strategy and behavior [see Werning (2012) and Bianchi and Melosi (2017)]. This paper differs from the existing literature in explicitly recognizing the asymmetric information between the private sector and the central bank. Wu and Xia (2016) pursue a related question using multi-factor shadow rate term structure models.

The paper is structured as follows: Section 2 presents the model; Section 3 discusses the solution method; Section 4 gives the results and provides discussion; Section 5 extends the model in Section 2 to the case with more than one unobservable shock; Section 6 concludes. Technical Appendix is available online at the author's website. 


\section{MODEL}

\subsection{The Basic New Keynesian Model}

The model in this paper builds on the basic new Keynesian model which consists of ${ }^{8}$

$$
\begin{gathered}
x_{t}=E_{t} x_{t+1}-\left(\hat{i}_{t}-E_{t} \pi_{t+1}\right)+u_{t}, \\
\pi_{t}=\beta E_{t} \pi_{t+1}+\kappa x_{t} .
\end{gathered}
$$

Equation (1) is referred to as the IS equation and equation (2) is the new Keynesian Phillips curve in the literature. ${ }^{9}$ Here, $E_{t}$ is a mathematical expectation based on the information set in $t, x_{t}$ is an output gap in $t, \pi_{t}$ is an inflation rate between $t$ and $t-1, \hat{i}_{t}$ is a nominal interest between $t$ and $t+1$ (as usual, the hat notation stands for the deviation of a variable from its steady-state value), $u_{t}$ is a demand shock in $t, \beta$ is the discount factor, and $\kappa$ is the slope of the Phillips curve which is itself a function of deep parameters. The demand shock is specified as an autoregressive process

$$
u_{t}=\rho u_{t-1}+\varepsilon_{t},
$$

where $|\rho|<1$ and $\varepsilon_{t} \stackrel{\text { i.i.d. }}{\sim} N\left(0, \sigma_{\varepsilon}\right)$ as commonly done in the literature. ${ }^{10}$

The model above is usually closed by adding an equation that specifies how the central bank sets the nominal interest rate. Typically, the zero lower bound literature considers interest rate rules of the form

$$
i_{t}=\max \left[0, i^{s s}+\phi_{x} x_{t}+\phi_{\pi} \pi_{t}\right],
$$

where $i^{s s}=\frac{1}{\beta}-1$ is the steady-state value of the (net) nominal interest rate $i_{t}$. This rule explicitly indicates that the nominal interest rate is bounded below at zero. Equivalently, it can be written as

$$
\hat{i}_{t}=\max \left[1-\frac{1}{\beta}, \phi_{x} x_{t}+\phi_{\pi} \pi_{t}\right]
$$

with the nominal interest rate now written as the deviation from its steady-state value. Equation (4) can be interpreted as a reaction function of the central bank to the policy relevant aggregate variables. Imposing the zero lower bound constraint on the nominal interest rate has an effect of increasing volatilities of the output gap and the inflation rate. This is so because at the zero lower bound, the nominal interest can no longer move downward to offset the effect of a negative demand shock on the output gap and the inflation rate. Basu and Bundick (2015) refer to this phenomenon as the endogenous volatility of the zero lower bound.

In what follows, the basic new Keynesian model above will be modified. The modification centers around the idea that there is an information asymmetry between the private sector and the central bank because the former cannot observe some information in the latter's information set directly. Whereas this information gap is resolved outside the zero lower bound, it continues to impinge on the economy inside the zero lower bound. It will be shown that this information loss makes 
the zero lower bound periods last longer and also magnifies the excess volatilities of the output gap and the inflation rate at the zero lower bound.

\subsection{Information Structure}

Unlike the basic new Keynesian model of the previous subsection, now assume that the central bank has a full information set at the beginning of each time period, but not the private sector. The central bank sets the nominal interest rate according to an interest rate rule which takes its information set as input. The private sector can invert this rule to extract a useful signal about what is missing in its own information set, and the revealed information will be used for the private sector's expectations formation. This is the sense in which the nominal interest rate movements have an additional informational value for the private sector. In this subsection, the information structure of the model will be discussed in detail.

The basic new Keynesian model in the previous subsection can be interpreted as a model in which its agents move sequentially but carry out their actions based on the same information set (as this model is observationally equivalent to the model in which the agents act simultaneously, as long as expectations are formed rationally). As explained above, the model in this paper departs from the basic model by altering the information structure. Here, the central bank moves first and sets the nominal interest rate based on its information set which is larger than the private sector's ex-ante. After observing the nominal interest rate, the private sector moves and engages in the signal extraction exercise. Based on the outcome of this exercise, it updates its information set and carries out its actions which determine the output gap and the inflation rate.

So, what is missing in the private sector's information set? In order to demonstrate the effect of the information problem at the zero lower bound, it is assumed that the current demand shock $u_{t}$ (which is also the natural rate of interest in this class of models) in the IS equation (1) is the only variable that is missing in the private sector's information set at the beginning of each time period prior to the signal extraction exercise. ${ }^{11,12}$ Because the demand shock is an important state variable for the private sector's expectation formation, associating the information problem at the zero lower bound with the demand shock can produce sizable effects on the endogenous variables. Fernández-Villaverde et al. (2015) result that negative demand shocks are important for the occurrence of the zero lower bound supports this choice as well. The use of the demand shock also allows incorporating the information problem without major modifications as this shock is already part of the standard new Keynesian model. Appendix A in the Supplementary Material discusses a more general information problem at the interest rate zero lower bound than the one in this subsection, a version of which is studied in Section 5. Appendix B in the Supplementary Material provides additional detail specific to the simple model here.

In the next subsection, it will be shown that when the zero lower bound constraint on the nominal interest rate does not bind, the private sector can retrieve 
the current demand shock exactly. In this case, the private sector and the central bank have the same information set ex-post. However, when the constraint binds, it can no longer retrieve the demand shock uniquely. This situation is referred to as the information problem at the zero lower bound. In this case, the private sector works with the conditional expected value of the demand shock instead. The private sector observes the true value of the current demand shock with at most one period delay: even when the zero lower bound constraint binds, its value becomes known at the end of the period. The short duration of the information delay is chosen in order to demonstrate that the information loss at the zero lower bound is costly even when the information asymmetry seems minor.

\subsection{Information Problem and Signal Extraction at the Zero Lower Bound}

The private sector agents condition their expectations on all the relevant information. This is the reason why they pay attention to the movements of the nominal interest rate which contain information about the current demand shock. However, they cannot extract the value of the current demand shock uniquely when the zero lower bound constraint on the nominal interest rate binds. In this subsection, this information problem at the zero lower bound will be discussed in detail. The functional form for the signal extraction at the zero lower bound, which is the main result of this subsection, will be derived using mathematical tools from microeconometrics.

2.3.1. Information problem at the zero lower bound. Suppose the zero lower bound constraint on the nominal interest rate does not bind. In this case, the private sector, after observing the nominal interest rate set by the central bank, can retrieve the value of the demand shock exactly. To see this, first note that the unconstrained solutions for the output gap $x_{t}$ and the inflation rate $\pi_{t}$ take the form

$$
x_{t}=\psi_{u}^{x} u_{t} \text { and } \pi_{t}=\psi_{u}^{\pi} u_{t}
$$

which are functions of the demand shock $u_{t}$ only as it is the only state variable. Substituting equation (5) into $\phi_{x} x_{t}+\phi_{\pi} \pi_{t}$ in equation (4) gives

$$
\hat{i}_{t}=\left(\phi_{x} \psi_{u}^{x}+\phi_{\pi} \psi_{u}^{\pi}\right) u_{t}
$$

which can be inverted to reveal that the value of the demand shock is

$$
u_{t}=\frac{\hat{i}_{t}}{\left(\phi_{x} \psi_{u}^{x}+\phi_{\pi} \psi_{u}^{\pi}\right)} .
$$

So, when the nominal interest rate is away from the zero lower bound, the demand shock can be recovered exactly. In this case, the information sets of the private sector and the central bank are ex-post identical and the resulting solution is equivalent to the one for the standard new Keynesian model without the zero lower bound constraint. ${ }^{13}$ 
Equation (6) ceases to hold when the nominal interest rate hits the zero lower bound. When this happens, the observed nominal interest rate $1-\frac{1}{\beta}$ does not necessarily coincide with the rate prescribed by $\phi_{x} x_{t}+\phi_{\pi} \pi_{t}$ in (4) as the latter can be any value less than or equal to the former:

$$
\left(\phi_{x} \psi_{u}^{x}+\phi_{\pi} \psi_{u}^{\pi}\right) u_{t} \leq 1-\frac{1}{\beta}
$$

Equivalently,

$$
u_{t} \leq \frac{1-\frac{1}{\beta}}{\left(\phi_{x} \psi_{u}^{x}+\phi_{\pi} \psi_{u}^{\pi}\right)}
$$

which shows that the demand shock is now consistent with a continuum of values. ${ }^{14}$ The private sector copes with this information problem at the zero lower bound by forming the conditional expected value of the demand shock [conditional on (7)] which we now turn to.

2.3.2. Signal extraction at the zero lower bound. The information problem at the zero lower bound poses a classical censored data problem in microeconometrics, which makes its mathematical tools relevant for deriving the conditional expected value of the demand shock. Substituting equation (3) into (7) gives

$$
\varepsilon_{t} \leq \frac{1-\frac{1}{\beta}}{\left(\phi_{x} \psi_{u}^{x}+\phi_{\pi} \psi_{u}^{\pi}\right)}-\rho u_{t-1}
$$

which defines an upper bound on $\varepsilon_{t}$. The right-hand side of (8) is denoted by $s_{t}$ henceforth. Equation (3) implies that the conditional expected value of the demand shock takes the form

$$
E_{t} u_{t}=\rho u_{t-1}+E\left[\varepsilon_{t} \mid \varepsilon_{t} \leq s_{t}\right],
$$

so the remaining task is to figure out what form $E\left[\varepsilon_{t} \mid \varepsilon_{t} \leq s_{t}\right]$ takes.

Because $\frac{\varepsilon_{t}}{\sigma_{\varepsilon}} \sim \Phi(\varepsilon)$ (standard normal distribution), it follows that the closedform solution of $E\left[\varepsilon_{t} \mid \varepsilon_{t} \leq s_{t}\right]$ can be obtained. To see this, let us start by rewriting $E\left[\varepsilon_{t} \mid \varepsilon_{t} \leq s_{t}\right]$ in the form that allows one to use the properties of the standard normal distribution. Conditioning the expected value of $\varepsilon_{t}$ on $\varepsilon_{t} \leq s_{t}$ is equivalent to conditioning on $\frac{\varepsilon_{t}}{\sigma_{\varepsilon}} \leq \frac{s_{t}}{\sigma_{\varepsilon}}$, so $E\left[\varepsilon_{t} \mid \varepsilon_{t} \leq s_{t}\right]=E\left[\varepsilon_{t} \mid \frac{\varepsilon_{t}}{\sigma_{\varepsilon}} \leq \frac{s_{t}}{\sigma_{\varepsilon}}\right]$. Multiplying and dividing this by $\sigma_{\varepsilon}$ gives $E\left[\varepsilon_{t} \mid \frac{\varepsilon_{t}}{\sigma_{\varepsilon}} \leq \frac{s_{t}}{\sigma_{\varepsilon}}\right]=\sigma_{\varepsilon} E\left[\frac{\varepsilon_{t}}{\sigma_{\varepsilon}} \mid \frac{\varepsilon_{t}}{\sigma_{\varepsilon}} \leq \frac{s_{t}}{\sigma_{\varepsilon}}\right]$. Because $\frac{\varepsilon_{t}}{\sigma_{\varepsilon}}$ is a standard normal random variable, $E\left[\frac{\varepsilon_{t}}{\sigma_{\varepsilon}} \mid \frac{\varepsilon_{t}}{\sigma_{\varepsilon}} \leq \frac{s_{t}}{\sigma_{\varepsilon}}\right]$ is the conditional expected value of a standard normal random variable whose closed-form expression is what we turn to now. Let $\tilde{\varepsilon}_{t}=\frac{\varepsilon_{t}}{\sigma_{\varepsilon}}$ and $\tilde{s}_{t}=\frac{s_{t}}{\sigma_{\varepsilon}}$ so that $E\left[\varepsilon_{t} \mid \varepsilon_{t} \leq s_{t}\right]=\sigma_{\varepsilon} E\left[\tilde{\varepsilon}_{t} \mid \tilde{\varepsilon}_{t} \leq \tilde{s}_{t}\right]$. It follows from using the properties of the standard normal distribution that

$$
E\left[\tilde{\varepsilon}_{t} \mid \tilde{\varepsilon}_{t} \leq \tilde{s}_{t}\right]=\int_{-\infty}^{\tilde{s}_{t}} \tilde{\varepsilon}_{t} \frac{\phi\left(\tilde{\varepsilon}_{t}\right)}{\Phi\left(\tilde{s}_{t}\right)} d \tilde{\varepsilon}_{t}=\int_{-\infty}^{\tilde{s}_{t}} \frac{\frac{d}{d \tilde{\varepsilon}_{t}}\left(-\phi\left(\tilde{\varepsilon}_{t}\right)\right)}{\Phi\left(\tilde{s}_{t}\right)} d \tilde{\varepsilon}_{t}=-\frac{\phi\left(\tilde{s}_{t}\right)}{\Phi\left(\tilde{s}_{t}\right)},
$$


which implies that

$$
E\left[\varepsilon_{t} \mid \varepsilon_{t} \leq s_{t}\right]=-\sigma_{\varepsilon} \frac{\phi\left(\tilde{s}_{t}\right)}{\Phi\left(\tilde{s}_{t}\right)},
$$

where $\phi($.$) and \Phi($.$) are the probability density function and the cumulative$ distribution function of a standard normal random variable.

Equation (10) is a non-linear function which relates the expected value of $\varepsilon_{t}$ to the observables. ${ }^{15}$ In microeconometrics, equation (10) is referred to as the inverse Mills ratio which serves as a central mathematical result for the analysis of censored data. ${ }^{16}$ Equation (10) is linearized in order to keep it consistent with the rest of the model. This does not mean that the model in this paper is linear: rather, it is piecewise linear with the zero lower bound constraint endogenously determining which regime prevails. To make sure that the result in this paper is not driven by large expectational errors of the private sector agents, the point of linearization $\tilde{s}$ is chosen to keep them small (more on this later). The linear approximation of (10) around $\tilde{s}$ is

$$
-\sigma_{\varepsilon} \frac{\phi\left(\tilde{s}_{t}\right)}{\Phi\left(\tilde{s}_{t}\right)} \simeq \gamma_{0}+\gamma_{u} u_{t-1},
$$

where

$$
\begin{gathered}
\gamma_{0}=-\sigma_{\varepsilon} \frac{\phi(\tilde{s})}{\Phi(\tilde{s})}+\frac{\phi(\tilde{s})(\tilde{s} \Phi(\tilde{s})+\phi(\tilde{s}))}{\Phi(\tilde{s})^{2}}\left(\frac{1-\frac{1}{\beta}}{\left(\phi_{x} \psi_{u}^{x}+\phi_{\pi} \psi_{u}^{\pi}\right)}-\sigma_{\varepsilon} \tilde{s}\right), \\
\gamma_{u}=-\frac{\phi(\tilde{s})(\tilde{s} \Phi(\tilde{s})+\phi(\tilde{s}))}{\Phi(\tilde{s})^{2}} \rho .
\end{gathered}
$$

Substituting (11) into (9) and collecting the like terms gives

$$
E_{t} u_{t} \simeq \gamma_{0}+\left(\rho+\gamma_{u}\right) u_{t-1}
$$

which is the private sector's conditional expected value of the demand shock at the zero lower bound. To cope with the information problem at the zero lower bound, the private sector uses (12) for making its decision. ${ }^{17}$

2.3.3. The rest of the model. The private sector agents, given the expected value of the current demand shock from the signal extraction exercise above, make their consumption and production decisions which lead to the IS equation

$$
E_{t} x_{t}=E_{t} x_{t+1}-\left(\hat{i}_{t}-E_{t} \pi_{t+1}\right)+E_{t} u_{t}
$$

and the Phillips curve

$$
E_{t} \pi_{t}=\beta E_{t} \pi_{t+1}+\kappa E_{t} x_{t},
$$

which subsume equations (1) and (2) as a special case in which the nominal interest rate is outside the zero lower bound $\left(E_{t} x_{t}=x_{t}\right.$ and $E_{t} \pi_{t}=\pi_{t}$ trivially in this case). ${ }^{18}$ The appearance of $E_{t} x_{t}$ in equations (13) and (14) reflects the information problem that the private sector faces inside the zero lower bound. 


\subsection{Summary}

Let us summarize the results in this section. The system of rational expectations equations which represents the economy is

1. $u_{t}=\rho u_{t-1}+\varepsilon_{t} ; \varepsilon_{t} \stackrel{\text { i.i.d. }}{\sim} N\left(0, \sigma_{\varepsilon}\right)$,

2. $\hat{i}_{t}=\max \left[1-\frac{1}{\beta}, \phi_{x} x_{t}+\phi_{\pi} \pi_{t}\right]$,

3. $E_{t} u_{t}=\left\{\begin{array}{cl}u_{t} & \text { if } \hat{i}_{t}>1-\frac{1}{\beta} \\ \gamma_{0}+\left(\rho+\gamma_{u}\right) u_{t-1} & \text { if } \hat{i}_{t} \leq 1-\frac{1}{\beta},\end{array}\right.$

4. $E_{t} x_{t}=E_{t} x_{t+1}-\left(\hat{i_{t}}-E_{t} \pi_{t+1}\right)+E_{t} u_{t}$,

5. $E_{t} \pi_{t}=\beta E_{t} \pi_{t+1}+\kappa E_{t} x_{t}$,

where $1-\frac{1}{\beta}$ is the value of the nominal interest rate at the zero lower bound (as a deviation from its steady-state value). The arrangement of the equations reflects the sequentiality in the model, except for the last two equations which are determined jointly by the private sector agents.

The actual output gap $x_{t}$ and inflation rate $\pi_{t}$ are related to their expected values according to

$$
\left[\begin{array}{c}
x_{t} \\
\pi_{t}
\end{array}\right]=\left[\begin{array}{c}
E_{t} x_{t} \\
E_{t} \pi_{t}
\end{array}\right]+\left[\begin{array}{c}
\frac{1}{1+\phi_{x}+\phi_{\pi} \kappa} \\
\frac{\kappa}{1+\phi_{x}+\phi_{\pi} \kappa}
\end{array}\right]\left(u_{t}-E_{t} u_{t}\right),
$$

if the economy is currently outside the zero lower bound (in which case, $x_{t}=E_{t} x_{t}$ and $\pi_{t}=E_{t} \pi_{t}$ because $\left.u_{t}=E_{t} u_{t}\right)$, and

$$
\left[\begin{array}{c}
x_{t} \\
\pi_{t}
\end{array}\right]=\left[\begin{array}{c}
E_{t} x_{t} \\
E_{t} \pi_{t}
\end{array}\right]+\left[\begin{array}{c}
1 \\
\kappa
\end{array}\right]\left(u_{t}-E_{t} u_{t}\right),
$$

if it is presently at the zero lower bound. Appendix D.4 in the Supplementary Material derives the expressions above for the extended model in Section 5 in the Supplementary Material whose special case corresponds to these. The form of the conditional expected value of the demand shock in 3 above highlights that the system is characterized by different stochastic processes depending on whether the zero lower bound on the nominal interest rate binds or not, which results from the information problem at the zero lower bound.

\section{SOLVING THE MODEL}

The model is solved by using the solution method of Guerrieri and Iacoviello $(2015)^{19}$ which generates a non-linear solution to a system of rational expectations equations with occasionally binding constraints. ${ }^{20}$ Their solution algorithm builds on the solution techniques of Jung et al. (2005) and Eggertsson and Woodford (2003).

In the context of the model here, Guerrieri and Iacoviello's algorithm generates the impulse response functions by (a) conjecturing the last period in which the 
zero lower bound constraint on the nominal interest rate binds, (b) solving the model backward from this last period to the initial period in which the constraint binds to generate a time-dependent solution, and (c) validating whether this solution is consistent with the conjecture about the last period in which the constraint binds. These steps are repeated until convergence. Their algorithm can also handle more complicated dynamics such as an oscillation in and out of the zero lower bound for the in-between periods. Appendix D.3 in the Supplementary Material provides additional detail in the context of the extended model in Section 5. The results there also apply to the baseline model that has been discussed so far.

\section{RESULTS}

Suppose the economy is pushed into the zero lower bound by persistently negative demand shocks. What are the consequences of the information problem at the zero lower bound? This section shows that the information problem brings about more negative output gap, larger deflation, and longer zero lower bound periods.

\subsection{Parametrization and Simulation}

In addition to the new Keynesian model with the information problem at the zero lower bound, the basic new Keynesian model with and without the zero lower bound constraint on the nominal interest rate (under a full and symmetric information setting) will be used for stochastic simulations.

Whereas the basic model without the zero lower bound constraint is the baseline model of the standard monetary economics textbooks (mentioned in Section 2.1), the model with the zero lower bound constraint (presented in Section 2.1) serves as one of the benchmark models in the zero lower bound literature. ${ }^{21}$ Comparing these two models to the model with the information problem allows one to study the effects of different mechanisms in an incremental manner: the inspection of dynamics under these three models allows one to separate the effect of the information problem at the zero lower bound from the effect of the zero lower bound constraint alone. In what follows, the model with the information problem will be labeled as "With ZLB \& IP," the model with the zero lower bound constraint only as "With ZLB," and the model without the constraint as "Without ZLB."

To illustrate the effect of a negative demand shock on the dynamics of the output gap, the inflation rate, and the nominal interest rate, the three models above will be subject to a two standard deviation negative innovation to the demand $\operatorname{shock}^{22}\left(\varepsilon_{1}=-0.001\right)$ initially in a neighborhood of the zero lower bound periods. Because the three models are practically identical outside the zero lower bound, this neighborhood is obtained from the actual simulation of "With ZLB" under a randomly generated sequence of demand shocks $\left(x_{0}=-0.0020\right.$, $\pi_{0}=-0.0059, \hat{i}_{0}=-0.0098$, and $\left.u_{0}=-0.0044\right)$. The motivation behind starting in the neighborhood of the zero lower bound rather than from the steady state 
is that the zero lower bound periods are a phenomenon that occurs sufficiently away from the steady state. The three models are simulated 1000 times each (by applying randomly generated sequences of demand shocks to them after the initial period) in order to generate distributions of possible paths of the output gap, the inflation rate, and the nominal interest rate. The results reported in this section are robust to using different neighborhoods of the zero lower bound periods.

The details about parametrization are as follows: the inverse of the Frisch labory supply elasticity $\eta=1$ and the discount factor $\beta=0.99$ which are consistent with each time period being interpreted as a quarter [see Galí (2008)]. $\kappa=0.1717$ which follows from the parameter values above and the Calvo price stickiness parameter [Calvo (1983)] $\theta=0.75 .^{23}$ This value of $\theta$ implies that firms change their prices once a year on average which is backed up by empirical evidence from micro data [see Álvarez et al. (2006)]. $\phi_{x}=0.5$ and $\phi_{\pi}=1.5$ are commonly used values in the literature [see Nakov (2008)]. To consider a scenario in which the output gap is persistently negative, $\rho=0.95$ and $\sigma_{\varepsilon}=0.0005$. The results reported in this section are robust to lower values of $\rho$, say $\rho=0.8$ [see Adam and Billi (2007)] or even lower values. Finally, $\tilde{s}=1.7$ [see (11)]. This value is selected to keep the private sector's expectational errors at the zero lower bound small (which prevents the results in this section from being driven by large expectational mistakes) as well as to achieve numerical stability (so that explosive dynamics are ruled out). The resulting dynamics are qualitatively similar under different values of $\tilde{s}$.

\subsection{Simulation Results}

Figure 1 gives the median paths of the output gap, the inflation rate, and the nominal interest rate (in level) under the three models when the economy is subject to a two standard deviation negative innovation to the demand shock. ${ }^{24}$ Recall that "Without ZLB" is the basic new Keynesian model without the zero lower bound constraint, "With ZLB" is the model with the zero lower bound constraint, and "With ZLB \& IP" is the model with the information problem at the zero lower bound. The figure shows that the models with the zero lower bound constraint (the latter two) exhibit negative output gap and deflation that are larger in magnitude. This is because the nominal interest rate cannot fall below zero to offset the effect of the negative demand shock in these models. This phenomenon has been discussed extensively in the zero lower bound literature. ${ }^{25}$ However, the figure also shows that the information problem at the zero lower bound reinforces the negative effect of the zero lower bound constraint on the aggregate variables: the output gap is more negative, the deflation is worse, and the zero lower bound periods are longer when the private sector faces the information problem.

Whereas the zero lower bound literature has considered the role of asymmetric information in credit markets in reinforcing the effect of the zero lower bound ${ }^{26}$, the role of asymmetric information between the private sector and the central bank has not been explored sufficiently. The above result demonstrates a novel 

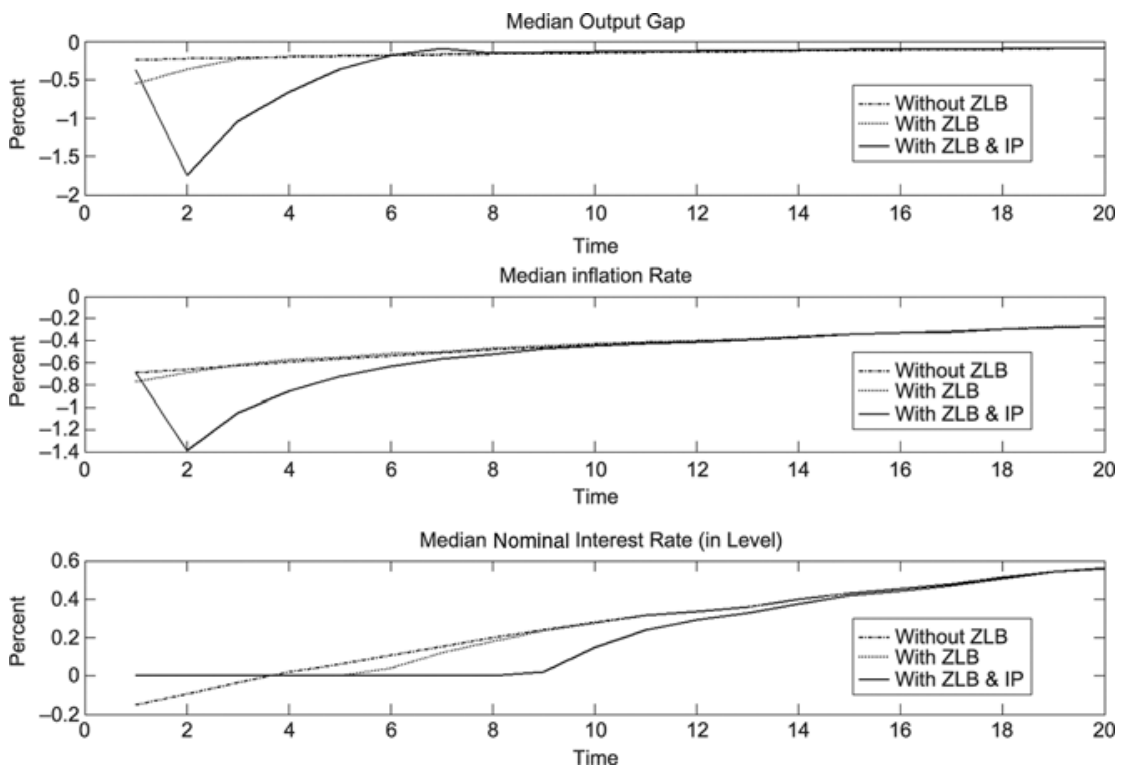

FIGURE 1. Median paths of endogenous variables. The figure provides the median paths of the output gap, the inflation rate, and the nominal interest rate (in level) based on 1000 simulation rounds. "Without ZLB" corresponds to the basic new Keynesian model without the zero lower bound constraint on the nominal interest rate, "With ZLB" to the model with the zero lower bound constraint, and "With ZLB \& IP" to the model with the information problem at the zero lower bound.

channel by which the zero lower bound impinges on the economy by showing that the interruption of the information flow from the central bank to the private sector at the zero lower bound is costly. Figure 2 provides the 10th percentiles and the 90th percentiles (dashed lines) of the output gap, the inflation rate, and the nominal interest rate (in level) in addition to their medians (solid lines). The 10th percentiles in the last two rows bring out the asymmetric shock responses imposed by the zero lower bound constraint.

What is the intuition behind this result? As discussed above, monetary policy cannot stabilize the negative demand shock at the zero lower bound, and this makes the economy more volatile. The information problem reinforces this outcome as it injects more volatility into the private sector agents' decision-making not only today but also in the future periods (as long as the zero lower bound binds), by making them unable to access information about the state of the economy. The negative effect of the increased uncertainty on the economy accords well with what was observed during the crisis of 2008/2009 and its aftermath (as reflected in financial indicators such as VIX index $)^{27}$ and provides a structured way to think about why the zero lower bound periods have been so painful and long-lived in many parts of the world. 

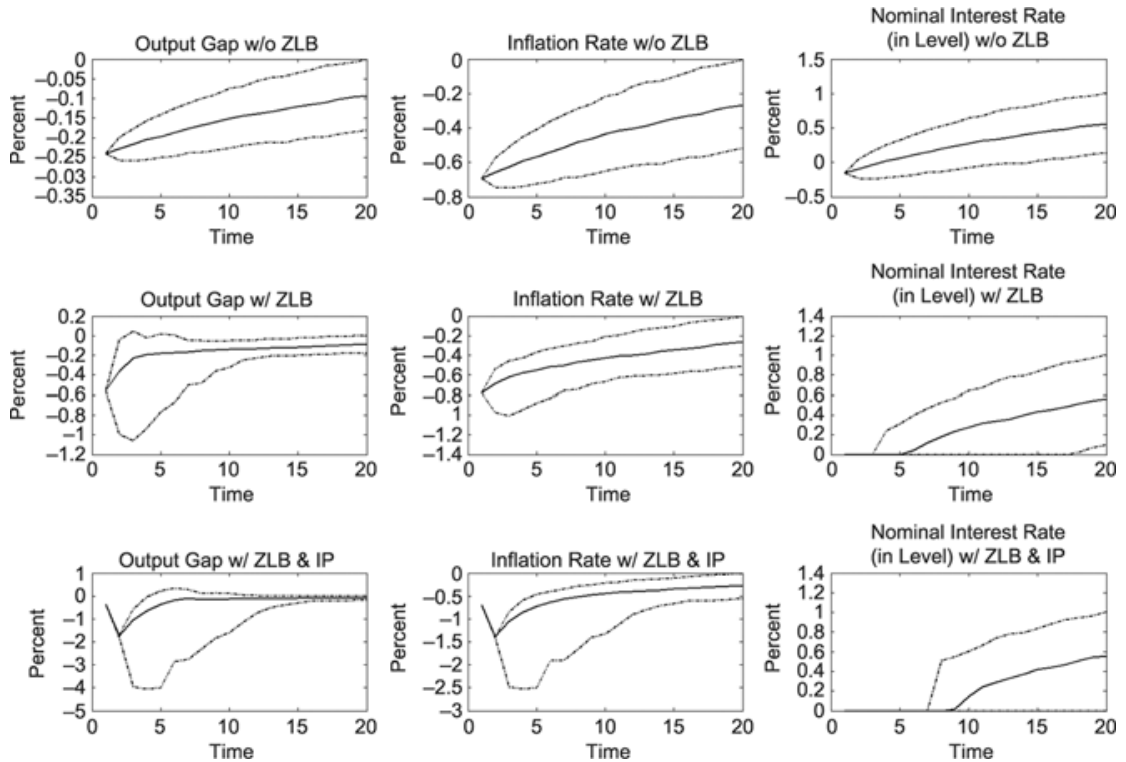

FIGURE 2. Distributions of endogenous variables. The solid lines are for the medians of the variables and the dashed lines are for the 10th and the 90th percentiles of the variables. The labeling conventions are identical to Figure 1.

Now, let us talk about the mechanics of this result. Suppose the economy is pushed into the zero lower bound as a result of a sequence of negative demand shocks. This brings about the information problem associated with the zero lower bound. Because the demand shocks are very persistent, the private sector agents expect to stay inside the zero lower bound beyond the current period and this implies that they expect to encounter the information problem in the future periods as well. The corresponding loss of information in the current period as well as the expected loss of information in the future periods interact with the forwardlooking nature of the new Keynesian model in such a way that the private sector agents expect the negative impact of the current demand shock to be more persistent over time [Their expectations are based on equation (12) rather than (3) inside the zero lower bound and this gives the extra persistence.].

Because the output gap and the inflation rate depend on the expected current and future demand shocks, ${ }^{28}$ the resulting sequence of the expected demand shocks makes the output gap and the inflation rate more negative and the nominal interest rate remains at the zero lower bound longer. Figure 3 provides the distribution of expectational errors (i.e., $e e_{t}=E_{t} u_{t}-u_{t}$ ) for the demand shock over time in percentage. The solid line plots the median path of the errors and the dashed lines plot the 10th and the 90th percentiles of the errors respectively. The figure confirms the analysis above: the expectational errors remain persistently negative inside the zero lower bound (i.e., $E_{t} u_{t}$ remains below $u_{t}$ ). It also confirms 


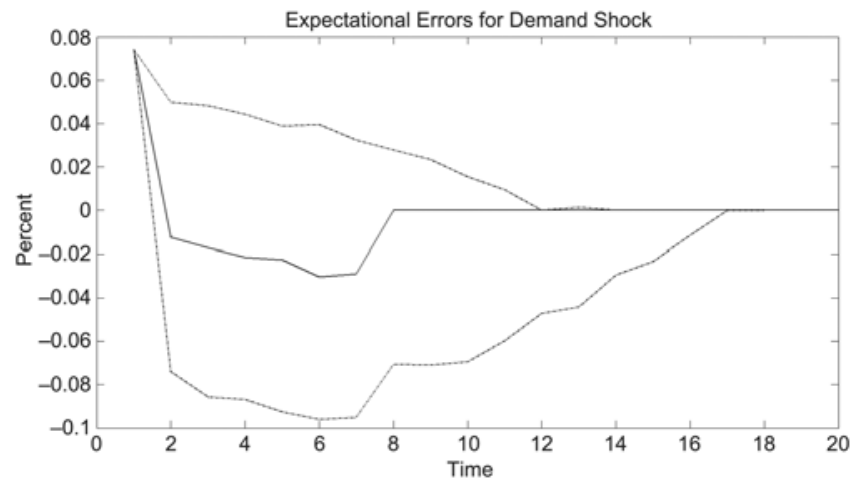

FIGURE 3. Distribution of expectational errors. The figure provides the distribution of the expectational errors for the demand shock over time which arise due to the information problem at the zero lower bound. The solid line is for the median path of the errors and the dashed lines are for the 10th and the 90th percentiles of the errors.

that the results in this section are not being driven by large expectational errors (the time average of the median expectational errors is practically zero).

Appendix C in the Supplementary Material presents how zero lower bound dynamics vary across different values of monetary policy coefficients $\phi_{x}$ and $\phi_{\pi}$. It shows that the median duration of the zero lower bound episode decreases as the policy coefficients become more aggressive toward stabilizing output gap and inflation.

\subsection{Discussion}

The economic crisis that started in 2008 and still affecting the world at the time of writing has taught economists that our understanding of economics at the zero lower bound is incomplete. In particular, it is not still clear why the zero lower bound has lasted so long and why it turned out to be so costly. This paper points to the interruption of information flow from the central bank to the private sector as one channel by which the zero lower bound impinges on the economy in addition to hampering policy maker's ability to stabilize negative shocks to the economy. As shown above, the basic three-equation new Keynesian model, which forms the basis of more elaborate models used by many central banks to inform monetary policy decisions, can be adapted to demonstrate how the information loss at the zero lower bound contributes to the further destabilization of the economy.

Because the model in this paper explicitly recognizes the information asymmetry between the private sector and the central bank, it provides an appropriate laboratory to think about forward guidance which has been adopted by major central banks as a policy instrument to overcome the constraints imposed by the zero lower bound on the conventional monetary policy. In essence, forward guidance 
involves communication about the future course of monetary policy in order to shape the public's expectations. There have been extensive discussions about pros and cons of forward guidance in the past few years. ${ }^{29}$

In the context of the model here, suppose that the central bank communicates with the private sector by announcing the value of the current demand shock. Because the output gap is less negative, the deflation is smaller in magnitude, and the zero lower bound periods are shorter in duration with the announcement (which corresponds to "With ZLB" where information is symmetric) than without (which corresponds to "With ZLB \& IP" where the information problem remains), the announcement is welfare-enhancing: the reduction of the private sector's uncertainty about the value of the demand shock allows the central bank to pursue its policy objective more efficiently. This type of forward guidance, which is concerned with transmission of information to public by a central bank, is called "Delphic" [Campbell et al. (2012)]. The above result suggests that when the central bank has an information advantage over the private sector, the revelation of information by forward guidance can be beneficial. ${ }^{30,31}$ The empirical evidence in support of central banks' information advantages ${ }^{32}$ provides a rationale to consider this result more seriously. However, the implementation of such policy may require careful considerations. For instance, Hernandez-Murillo and Shell's (2014) finding that the FOMC statements have grown in complexity since the crisis of 2008/2009 suggests that in addition to sharing more information about the state of the economy, central banks also need to pay more attention to getting their messages understood by public.

\section{EXTENSION}

This section deals with a model setting where there is more than one currently unobservable shock. This extension is demonstrated with the basic new Keynesian model with both demand and supply shocks, which builds on the baseline model in Section 2. It will be shown that zero lower bound episodes are both longer and more costly in this case, especially with the information problem at the zero lower bound.

\subsection{Extended Model}

For the ease of exposition, the information problem at the zero lower bound was analyzed above within a simple setting where there is only one currently unobservable shock. In what follows, this will be extended to the case with more than one currently unobservable shock. The extension will be illustrated with the minimum modification of the baseline model above. Specifically, the basic new Keynesian model now features the supply shock $e_{t}$ in the Phillips curve:

$$
\pi_{t}=\beta E_{t} \pi_{t+1}+\kappa x_{t}+e_{t} .
$$


It is assumed that the supply shock follows an autoregressive process

$$
e_{t}=\rho_{e} e_{t-1}+\varepsilon_{t}^{e} \text { where } \varepsilon_{t}^{e} \stackrel{i . i . d .}{\sim} N\left(0, \sigma_{e}^{2}\right),
$$

which is the standard assumption. ${ }^{33}$ The notation for the demand shock is slightly altered due to the inclusion of the supply shock: ${ }^{34}$

$$
u_{t}=\rho_{u} u_{t-1}+\varepsilon_{t}^{u} \text { where } \varepsilon_{t}^{u} \stackrel{i . i . d .}{\sim} N\left(0, \sigma_{u}^{2}\right) .
$$

Both $\rho_{u}$ and $\rho_{e}$ are assumed to be less than one in absolute values. The rest of the model are identical to those in Section 2. In what follows, the information problem will be studied in the context of this extended model.

\subsection{Information Problem and Signal Extraction at the Zero Lower Bound}

With more than one currently unobservable shock in the model, the information asymmetry between the central bank and the private sector remains even outside the zero lower bound: what the private sector recovers from the nominal interest rate in this case is a linear combination of the unobservables as opposed to the unobservables themselves (see Appendix A in the Supplementary Material). To cope with this, the private sector utilizes the Kalman filter to form conditional expectations about the unobservables. As before, currently unobservable shocks, which are the demand and supply shocks in the context of the illustrative model, are assumed to be observed with one period delay so that the results in this section are consistently comparable to those in the previous section.

5.2.1. Solution outside the zero lower bound. The economy outside the zero lower bound corresponds to a partial information rational expectations model of Pearlman et al. (1986). The model consists of equations (1) and (15)-(17), and the interest rate rule which are collected here for the ease of reference:

1. $x_{t}=E_{t} x_{t+1}-\left(\hat{i}_{t}-E_{t} \pi_{t+1}\right)+u_{t}$,

2. $u_{t}=\rho_{u} u_{t-1}+\varepsilon_{t}^{u}$ where $\varepsilon_{t}^{u} \stackrel{\text { i.i.d. }}{\sim} N\left(0, \sigma_{u}^{2}\right)$,

3. $\pi_{t}=\beta E_{t} \pi_{t+1}+\kappa x_{t}+e_{t}$,

4. $e_{t}=\rho_{e} e_{t-1}+\varepsilon_{t}^{e}$ where $\varepsilon_{t}^{e} \stackrel{\text { i.i.d. }}{\sim} N\left(0, \sigma_{e}^{2}\right)$,

5. $\hat{i}_{t}=\phi_{x} x_{t}+\phi_{\pi} \pi_{t}$.

The assumed information structure implies that only $\hat{i}_{t}$ is currently observable, and $x_{t}, \pi_{t}, u_{t}$, and $e_{t}$ are observed with one period delay. Hence, the information structure is similar to the one in Section 2, except for the fact that now the private sector agents observe only the linear combination of the innovations $\varepsilon_{t}^{u}$ and $\varepsilon_{t}^{e}$ (or equivalently the shocks $u_{t}$ and $e_{t}$ ) through $\hat{i}_{t}$, not their individual values, outside the zero lower bound.

In the state space representation of Pearlman et al. (1986), a generic model under partial information takes the form 


$$
\begin{gathered}
{\left[\begin{array}{c}
z_{t+1} \\
E_{t} q_{t+1}
\end{array}\right]=G\left[\begin{array}{l}
z_{t} \\
q_{t}
\end{array}\right]+H\left[\begin{array}{l}
E_{t} z_{t} \\
E_{t} q_{t}
\end{array}\right]+n_{t},} \\
w_{t}=K\left[\begin{array}{l}
z_{t} \\
q_{t}
\end{array}\right]+L\left[\begin{array}{c}
E_{t} z_{t} \\
E_{t} q_{t}
\end{array}\right]+v_{t},
\end{gathered}
$$

where $z_{t}$ is a vector of predetermined variables ( $u_{t}$ and $e_{t}$ in the model), $q_{t}$ is a vector of non-predetermined variables ( $x_{t}$ and $\pi_{t}$ in the model), $n_{t}$ is a vector of white noise innovations ( $\varepsilon_{t+1}^{u}$ and $\varepsilon_{t+1}^{e}$ in the model), $w_{t}$ is a vector of currently observable variables ( $\hat{i}_{t}$ in the model), and $v_{t}$ is a vector of white noise measurement errors (which is assumed to be nil). The first equation is the state equation and the second equation the observation equation. The Kalman filter, which is specialized to the assumption of one period delay in observability, provides expected values of $\varepsilon_{t}^{u}$ and $\varepsilon_{t}^{e}$ conditional on the observables, which includes the linear combination of $\varepsilon_{t}^{u}$ and $\varepsilon_{t}^{e}$. The solution is obtained by combining these filtered expectations with the solution for a system of linear rational expectations equations. Appendix D.1 in the Supplementary Material recasts the model above in this representation and obtains the solution which takes the form

$$
\begin{gathered}
z_{t}=\psi_{z}^{z} z_{t-1}+n_{t-1}^{1}, \\
q_{t}=\psi_{z}^{q} z_{t-1}+\psi_{n^{1}} n_{t-1}^{1}, \\
w_{t}=K_{2} q_{t} .
\end{gathered}
$$

These equations describe the evolution of the economy outside the zero lower bound.

5.2.2. Information problem at the zero lower bound. It follows from equations (19) and (20) that the nominal interest rate outside the zero lower bound takes the form

$$
w_{t}=\hat{i}_{t}=\underbrace{\left[\begin{array}{ll}
\phi_{x} \phi_{\pi}
\end{array}\right]}_{=K_{2}} \underbrace{\left[\begin{array}{c}
x_{t} \\
\pi_{t}
\end{array}\right]}_{=q_{t}}=\left[\phi_{x} \phi_{\pi}\right]\left[\psi_{=z_{t-1}^{q}}^{\left[\begin{array}{c}
u_{t-1} \\
e_{t-1}
\end{array}\right]}+\psi_{n^{1}}^{\left[\begin{array}{c}
\varepsilon_{t}^{u} \\
\varepsilon_{t}^{e}
\end{array}\right]}\right],
$$

where

$$
\psi_{z}^{q}=\left[\begin{array}{cc}
\psi_{u}^{x} & \psi_{e}^{x} \\
\psi_{u}^{\pi} & \psi_{e}^{\pi}
\end{array}\right] \text { and } \psi_{n^{1}}=\left[\begin{array}{cc}
\psi_{\varepsilon^{u}}^{x} & \psi_{\varepsilon^{e}}^{x} \\
\psi_{\varepsilon^{u}}^{\pi} & \psi_{\varepsilon^{e}}^{\pi}
\end{array}\right]
$$

give the elements of the coefficient matrices above. ${ }^{35}$ This expression can be rewritten as

$$
\hat{i_{t}}=\varphi_{u} u_{t-1}+\varphi_{e} e_{t-1}+\varphi_{\varepsilon^{u}} \varepsilon_{t}^{u}+\varphi_{\varepsilon} \varepsilon_{t}^{e},
$$

where

$$
\begin{aligned}
& \varphi_{u}=\phi_{x} \psi_{u}^{x}+\phi_{\pi} \psi_{u}^{\pi}, \\
& \varphi_{e}=\phi_{x} \psi_{e}^{x}+\phi_{\pi} \psi_{e}^{\pi},
\end{aligned}
$$




$$
\begin{aligned}
& \varphi_{\varepsilon^{u}}=\phi_{x} \psi_{\varepsilon^{u}}^{x}+\phi_{\pi} \psi_{\varepsilon^{u}}^{\pi}, \\
& \varphi_{\varepsilon^{e}}=\phi_{x} \psi_{\varepsilon^{e}}^{x}+\phi_{\pi} \psi_{\varepsilon^{e}}^{\pi} .
\end{aligned}
$$

Substituting equation (21) into (4) gives the inequality that expresses the information problem at the zero lower bound:

$$
\varphi_{\varepsilon^{u}} \varepsilon_{t}^{u}+\varphi_{\varepsilon^{e}} \varepsilon_{t}^{e} \leq 1-\frac{1}{\beta}-\varphi_{u} u_{t-1}-\varphi_{e} e_{t-1}
$$

Equation (22) imposes a restriction on the linear combination of two currently unobservable shocks $\varepsilon_{t}^{u}$ and $\varepsilon_{t}^{e}$, which is consistent with a continuum of tuples of $\left(\varepsilon_{t}^{u}, \varepsilon_{t}^{e}\right)$. This parallels equation (7) in Section 2.3.1 which states the information problem for the model with only one unobservable shock.

5.2.3. Signal extraction at the zero lower bound. The augmentation of the supply shock to the Phillips curve complicates the signal extraction problem at the zero lower bound. The conditional expectations of $\varepsilon_{t}^{u}$ and $\varepsilon_{t}^{e}$ at the zero lower bound are

$$
E\left[\varepsilon_{t}^{u} \mid \varphi_{\varepsilon^{u}} \varepsilon_{t}^{u}+\varphi_{\varepsilon^{e}} \varepsilon_{t}^{e} \leq s_{t}\right] \simeq \gamma_{0}^{u}+\gamma_{u}^{u} u_{t-1}+\gamma_{e}^{u} e_{t-1}
$$

where

$$
\begin{aligned}
& \gamma_{0}^{u}=-\sigma_{u} \int_{-\infty}^{\infty} \frac{\phi\left(s_{t}^{e}\right)}{\Phi\left(s_{t}^{e}\right)} \phi\left(\tilde{\varepsilon}_{t}^{e}\right) d \tilde{\varepsilon}_{t}^{e} \\
&+\int_{-\infty}^{\infty} \frac{\phi\left(s_{t}^{e}\right)\left[s_{t}^{e} \Phi\left(s_{t}^{e}\right)+\phi\left(s_{t}^{e}\right)\right]}{\Phi\left(s_{t}^{e}\right)^{2}} \phi\left(\tilde{\varepsilon}_{t}^{e}\right) d \tilde{\varepsilon}_{t}^{e} \times\left[\frac{1-\frac{1}{\beta}-s}{\varphi_{\varepsilon^{u}}}\right], \\
& \gamma_{u}^{u}=-\frac{\varphi_{u}}{\varphi_{\varepsilon^{u}}} \int_{-\infty}^{\infty} \frac{\phi\left(s_{t}^{e}\right)\left[s_{t}^{e} \Phi\left(s_{t}^{e}\right)+\phi\left(s_{t}^{e}\right)\right]}{\Phi\left(s_{t}^{e}\right)^{2}} \phi\left(\tilde{\varepsilon}_{t}^{e}\right) d \tilde{\varepsilon}_{t}^{e}, \\
& \gamma_{e}^{u}=-\frac{\varphi_{e}}{\varphi_{\varepsilon^{u}}} \int_{-\infty}^{\infty} \frac{\phi\left(s_{t}^{e}\right)\left[s_{t}^{e} \Phi\left(s_{t}^{e}\right)+\phi\left(s_{t}^{e}\right)\right]}{\Phi\left(s_{t}^{e}\right)^{2}} \phi\left(\tilde{\varepsilon}_{t}^{e}\right) d \tilde{\varepsilon}_{t}^{e},
\end{aligned}
$$

and

$$
E\left[\varepsilon_{t}^{e} \mid \varphi_{\varepsilon^{u}} \varepsilon_{t}^{u}+\varphi_{\varepsilon^{e}} \varepsilon_{t}^{e} \leq s_{t}\right] \simeq \gamma_{0}^{e}+\gamma_{u}^{e} u_{t-1}+\gamma_{e}^{e} e_{t-1},
$$

where

$$
\begin{aligned}
\gamma_{0}^{e}= & -\sigma_{e} \int_{-\infty}^{\infty} \frac{\phi\left(s_{t}^{u}\right)}{\Phi\left(s_{t}^{u}\right)} \phi\left(\tilde{\varepsilon}_{t}^{u}\right) d \tilde{\varepsilon}_{t}^{u} \\
& +\int_{-\infty}^{\infty} \frac{\phi\left(s_{t}^{u}\right)\left[s_{t}^{u} \Phi\left(s_{t}^{u}\right)+\phi\left(s_{t}^{u}\right)\right]}{\Phi\left(s_{t}^{u}\right)^{2}} \phi\left(\tilde{\varepsilon}_{t}^{u}\right) d \tilde{\varepsilon}_{t}^{u} \times\left[\frac{1-{ }_{f}^{1}-s}{\varphi_{\varepsilon^{e}}}\right],
\end{aligned}
$$




$$
\begin{aligned}
& \gamma_{u}^{e}=-\frac{\varphi_{u}}{\varphi_{\varepsilon^{e}}} \int_{-\infty}^{\infty} \frac{\phi\left(s_{t}^{u}\right)\left[s_{t}^{u} \Phi\left(s_{t}^{u}\right)+\phi\left(s_{t}^{u}\right)\right]}{\Phi\left(s_{t}^{u}\right)^{2}} \phi\left(\tilde{\varepsilon}_{t}^{u}\right) d \tilde{\varepsilon}_{t}^{u}, \\
& \gamma_{e}^{e}=-\frac{\varphi_{e}}{\varphi_{\varepsilon^{e}}} \int_{-\infty}^{\infty} \frac{\phi\left(s_{t}^{u}\right)\left[s_{t}^{u} \Phi\left(s_{t}^{u}\right)+\phi\left(s_{t}^{u}\right)\right]}{\Phi\left(s_{t}^{u}\right)^{2}} \phi\left(\tilde{\varepsilon}_{t}^{u}\right) d \tilde{\varepsilon}_{t}^{u}
\end{aligned}
$$

with

$$
\begin{gathered}
s_{t}=1-\frac{1}{\beta}-\varphi_{u} u_{t-1}-\varphi_{e} e_{t-1,} \\
s_{t}^{e}=\frac{s}{\varphi_{\varepsilon^{u}}} \frac{1}{\sigma_{u}}-\frac{\varphi_{\varepsilon^{e}}}{\varphi_{\varepsilon^{u}}} \frac{\sigma_{e}}{\sigma_{u}} \tilde{\varepsilon}_{t}^{e}, \\
s_{t}^{u}=\frac{s}{\varphi_{\varepsilon} e} \frac{1}{\sigma_{e}}-\frac{\varphi_{\varepsilon^{u}}}{\varphi_{\varepsilon^{e}}} \frac{\sigma_{u}}{\sigma_{e}} \tilde{\varepsilon}_{t}^{u} .
\end{gathered}
$$

$\tilde{\varepsilon}_{t}^{u}$ and $\tilde{\varepsilon}_{t}^{e}$ follow the standard normal distribution, and $\varphi_{\varepsilon^{u}}$ and $\varphi_{\varepsilon^{e}}$ are defined in equation (21). $s$ denotes a value of $s_{t}$ at which the conditional expectations above are approximated. ${ }^{36}$ The approximations (23) and (24) are derived in Appendix D.2 in the Supplementary Material. When $\varepsilon_{t}^{e}$ is not part of the model, $\gamma_{0}^{u}=\gamma_{0}, \gamma_{u}^{u}=\gamma_{u}$, and $\gamma_{e}^{u}=0$ : the coefficients reduce to those for the simpler model in Section 2.3.2 [see (11)] where the demand shock $u_{t}$ is the only unobservable shock. $\gamma_{0}^{e}=\gamma_{u}^{e}=\gamma_{e}^{e}=0$ by definition in this case.

The conditional expected value of $u_{t}$ and $e_{t}$ at the zero lower bound takes the form

$$
\begin{aligned}
& E_{t} u_{t} \simeq \gamma_{0}^{u}+\left(\rho_{u}+\gamma_{u}^{u}\right) u_{t-1}+\gamma_{e}^{u} e_{t-1}, \\
& E_{t} e_{t} \simeq \gamma_{0}^{e}+\left(\rho_{e}+\gamma_{e}^{e}\right) e_{t-1}+\gamma_{u}^{e} u_{t-1},
\end{aligned}
$$

respectively, which parallel the expression for $E_{t} u_{t}$ in (12) for the simpler model with only one unobservable shock.

The generalization of the signal extraction rules above to the case with $n$ currently unobservable shocks is provided in Appendix D.2 in the Supplementary Material.

\subsection{Summary}

The economy is represented by the system of equations

1. $u_{t}=\rho_{u} u_{t-1}+\varepsilon_{t}^{u}$ where $\varepsilon_{t}^{u} \stackrel{i . i . d .}{\sim} N\left(0, \sigma_{u}^{2}\right)$,

2. $e_{t}=\rho_{e} e_{t-1}+\varepsilon_{t}^{e}$ where $\varepsilon_{t}^{e} \stackrel{i . i . d .}{\sim} N\left(0, \sigma_{e}^{2}\right)$,

3. $\hat{i}_{t}=\max \left[1-\frac{1}{\beta}, \phi_{x} x_{t}+\phi_{\pi} \pi_{t}\right]$,

4. $E_{t} u_{t}=\left\{\begin{array}{cc}\rho_{u} u_{t-1}+\gamma_{\varepsilon^{u}}^{\varepsilon^{u}} \varepsilon_{t}^{u}+\gamma_{\varepsilon^{e}}^{\varepsilon^{u}} \varepsilon_{t}^{e} & \text { if } \hat{i}_{t}>1-\frac{1}{\beta} \\ \gamma_{0}^{u}+\left(\rho_{u}+\gamma_{u}^{u}\right) u_{t-1}+\gamma_{e}^{u} e_{t-1} & \text { if } \hat{i}_{t} \leq 1-\frac{1}{\beta},\end{array}\right.$

5. $E_{t} e_{t}=\left\{\begin{array}{cc}\rho_{e} e_{t-1}+\gamma_{\varepsilon^{u}}^{\varepsilon^{e}} \varepsilon_{t}^{u}+\gamma_{\varepsilon^{e}}^{\varepsilon^{e}} \varepsilon_{t}^{e} & \text { if } \hat{i}_{t}>1-\frac{1}{\beta} \\ \gamma_{0}^{e}+\left(\rho_{e}+\gamma_{e}^{e}\right) e_{t-1}+\gamma_{u}^{e} u_{t-1} & \text { if } \hat{i}_{t} \leq 1-\frac{1}{\beta},\end{array}\right.$ 
6. $E_{t} x_{t}=E_{t} x_{t+1}-\left(\hat{i}_{t}-E_{t} \pi_{t+1}\right)+E_{t} u_{t}$,

7. $E_{t} \pi_{t}=\beta E_{t} \pi_{t+1}+\kappa E_{t} x_{t}+E_{t} e_{t}$.

The arrangement of the equations above reflects the sequentiality in the model. The expressions for $\gamma_{\varepsilon^{u}}^{\varepsilon^{u}}$ and $\gamma_{\varepsilon^{e}}^{\varepsilon^{u}}$ in (4) and $\gamma_{\varepsilon^{u}}^{\varepsilon^{e}}$ and $\gamma_{\varepsilon^{e}}^{\varepsilon^{e}}$ in (5) are derived in Appendix D.3.1 in the Supplementary Material, and (6) and (7) are adjusted according to

$$
\left[\begin{array}{c}
x_{t} \\
\pi_{t}
\end{array}\right]=\left[\begin{array}{c}
E_{t} x_{t} \\
E_{t} \pi_{t}
\end{array}\right]+\left[\begin{array}{cc}
\frac{1}{1+\phi_{x}+\phi_{\pi} \kappa} & -\frac{\phi_{\pi}}{1+\phi_{x}+\phi_{\pi} \kappa} \\
\frac{\kappa}{1+\phi_{x}+\phi_{\pi} \kappa} & \frac{1+\phi_{x}}{1+\phi_{x}+\phi_{\pi} \kappa}
\end{array}\right]\left(\left[\begin{array}{c}
u_{t} \\
e_{t}
\end{array}\right]-\left[\begin{array}{c}
E_{t} u_{t} \\
E_{t} e_{t}
\end{array}\right]\right),
$$

if the economy is presently outside the zero lower bound, and

$$
\left[\begin{array}{c}
x_{t} \\
\pi_{t}
\end{array}\right]=\left[\begin{array}{c}
E_{t} x_{t} \\
E_{t} \pi_{t}
\end{array}\right]+\left[\begin{array}{ll}
1 & 0 \\
\kappa & 1
\end{array}\right]\left(\left[\begin{array}{l}
u_{t} \\
e_{t}
\end{array}\right]-\left[\begin{array}{c}
E_{t} u_{t} \\
E_{t} e_{t}
\end{array}\right]\right),
$$

if it is currently at the zero lower bound. These relationships are derived in Appendix D.4 in the Supplementary Material.

\subsection{Results}

The model is again solved using the solution method of Guerrieri and Iacoviello (2015). Appendix D.3 in the Supplementary Material explains how to take the model here to the solution method without violating the assumed information structure. The supply shock process in equation (16) is parameterized as $\rho_{e}=0.70$ and $\sigma_{e}=0.00025$. Hence, the supply shock considered here is both less persistent and less noisy compared to the demand shock. ${ }^{37}$ The model parametrization remains unchanged otherwise to make sure that the results here are comparable to those in Section 4. Appendix D.5 in the Supplementary Material discusses how to calibrate $s$ in (23) and (24) to attain the comparability.

5.4.1. Responses to the demand shock. Figure 4 shows the median path of the output gap, the inflation rate, and the nominal interest rate subject to a two standard deviation negative innovation to the demand shock $\left(\varepsilon_{1}^{u}=-0.001\right)$. The model is simulated from the same initial point as the one in Section 4 (with $u_{0}=-0.0044$ and $e_{0}=e_{1}=0$ ) so that the results here are as comparable to those in Figure 1 as possible. The aim is to show how the augmentation of the model in Section 2 with the supply shock alters the zero lower bound dynamics in an otherwise identical environment. "Without ZLB" corresponds to the full and symmetric information new Keynesian model without the zero lower bound constraint. "With ZLB" is the model subject to the zero lower bound constraint, but with Delphic forward guidance where the linear combination of the shocks

$$
D n_{t-1}^{1}=\left[\frac{\phi_{x}+\phi_{\pi} \kappa}{1+\phi_{x}+\phi_{\pi} \kappa} \frac{\phi_{\pi}}{1+\phi_{x}+\phi_{\pi} \kappa}\right]\left[\begin{array}{c}
\varepsilon_{t}^{u} \\
\varepsilon_{t}^{e}
\end{array}\right]
$$



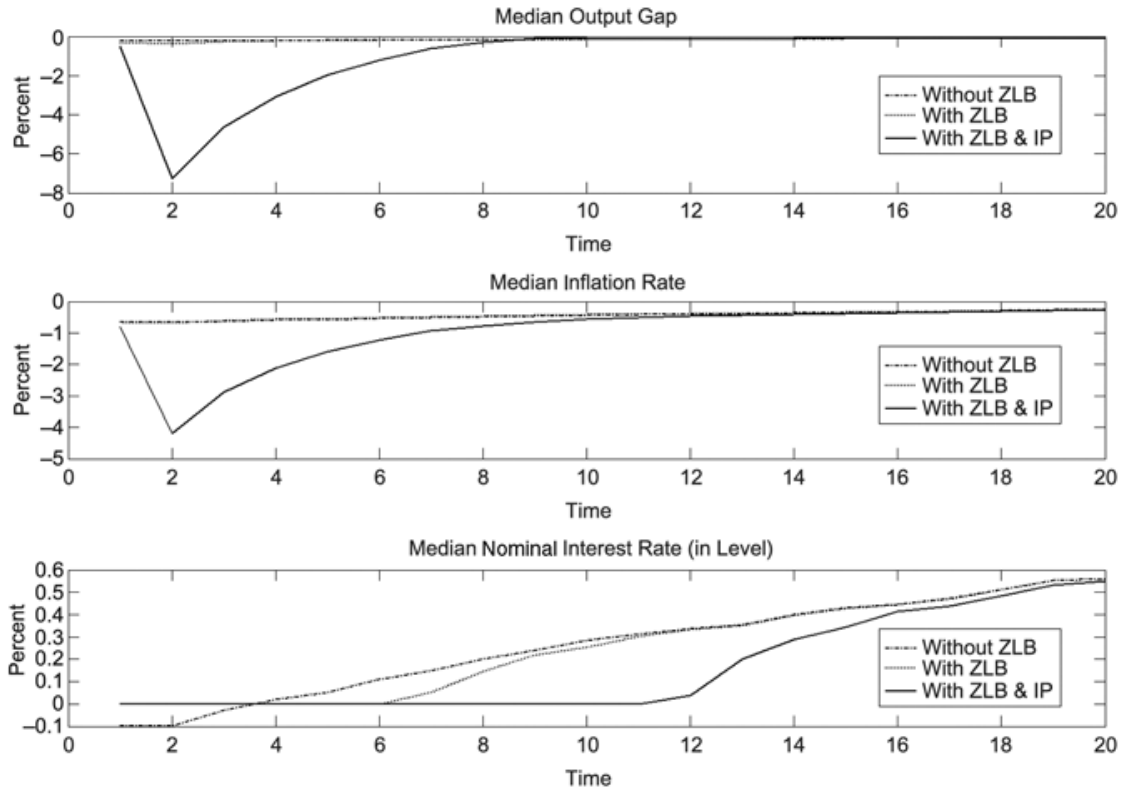

FigURE 4. Median paths of endogenous variables (demand shock). The figure convention is identical to that for Figure 1.

is announced by the central bank to the private sector at the zero lower bound. This is what the latter backs out on its own outside the zero lower bound (but not the actual values of the shocks/innovations; see Appendices A, D.1, and D.3.1 in the Supplementary Material for additional detail). "With ZLB \& IP" is the model with the information problem at the zero lower bound where such announcement is absent. It shows that the zero lower bound episode is both longer and more costly (as evidenced by larger output gap loss and deflation) relative to the baseline model featuring only the demand shock, especially in the presence of the information problem. The result is the sum of two effects. First, the existence of the additional shock makes the economy more volatile in itself. In addition to this, it also complicates the signal extraction at the zero lower bound as demonstrated in Section 5.2.3. For this reason, the Delphic forward guidance above can reduce the cost of the zero lower bound. However, the reduction is not as strong as when the actual value of each shocks is announced, which corresponds to "With ZLB" in Figure 1 . This is due to the fact that the information asymmetry between the central bank and the private sector continues to remain outside the zero lower bound with the limited form of forward guidance above. These findings are robust across a wide set of parametrizations, which are essentially a numerically feasible set.

5.4.2. Responses to the supply shock. Figure 5 gives the median path of the same variables subject to a two standard deviation negative innovation to the supply shock $\left(\varepsilon_{1}^{e}=-0.0005\right)$. For this simulation, the initial condition for the supply 

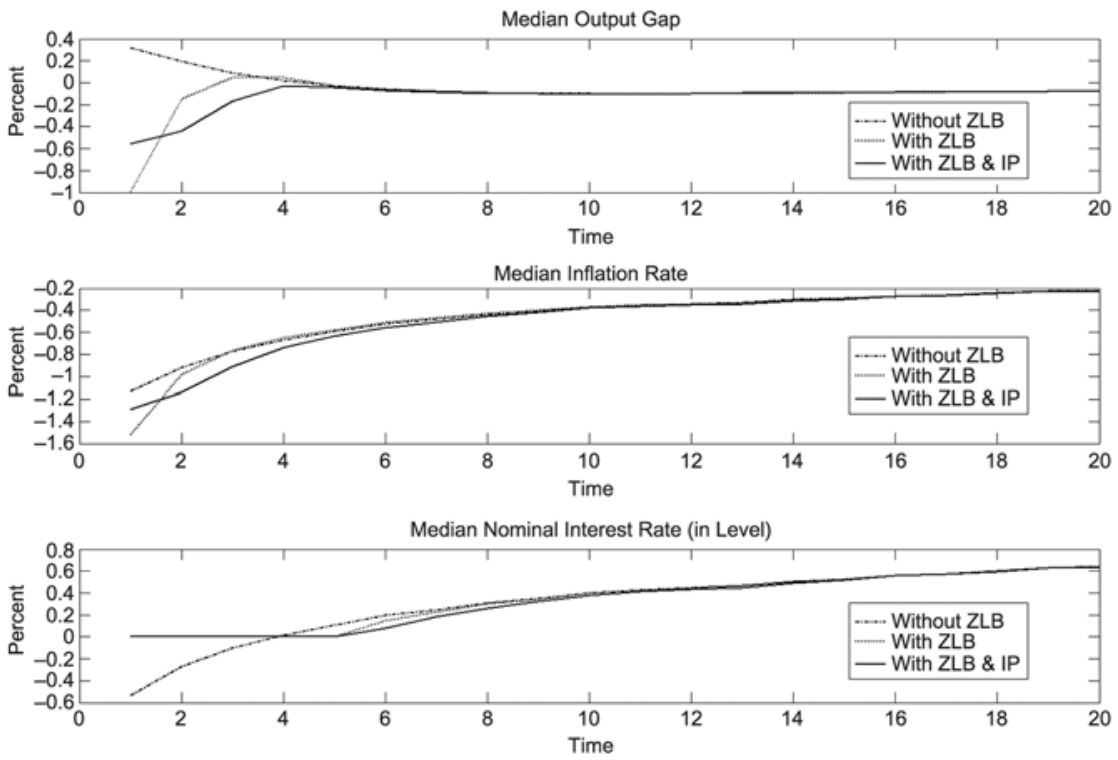

FigURE 5. Median paths of endogenous variables (supply shock). The figure convention is identical to that for Figure 1.

shock $e_{0}=-0.003$ so that the presumed history of the supply shocks is consistent with the possibility of the zero lower bound. As expected, in the absence of the zero lower bound constraint and imperfect information, the supply shock brings about the well-known trade-off between output gap and inflation. This corresponds to "Without ZLB" in the figure. However, the zero lower bound constraint takes away this trade-off, which reflects the fact that the private sector cannot be certain about the nature of the shocks they face due to the asymmetric information structure. Whereas the median duration of the zero lower bound is the same for these cases, the output gap loss and the deflationary developments are worse with the information problem ("With ZLB \& IP") than without ("With ZLB"). With a supply shock innovation larger than the one above, the former leads to a longer zero lower bound episode than the latter, which is also more costly in terms of output gap and inflation variances.

\section{CONCLUSION}

Why is a zero lower bound episode disruptive and long-lasting? This paper demonstrates that the private sector's information loss at the zero lower bound can lead to an extended duration of zero lower bound episodes, which are accompanied by more severe deflation and more negative output gap. This result is based on the standard new Keynesian model that is modified to reflect the central bank's information advantages over the private sector. 
It is a well-known result that the zero lower bound on the nominal interest rate can lead to endogenous volatility as it hampers the central bank's ability to offset negative shocks to the economy. By recognizing the private sector agents' information problem at the zero lower bound, this paper illustrates how the increased uncertainty serves as a channel by which the zero lower bound periods become prolonged and more costly. Hence, the paper provides a novel framework to discuss the role of information frictions in exacerbating the cost of the zero lower bound episodes.

The above result naturally leads to the question of whether forward guidance can reduce the duration and cost of the zero lower bound. This paper shows that when forward guidance takes the form of information revelation to the private sector, the answer is positive. Thus, the paper provides a theoretical underpinning for forward guidance which is concerned with information transmission to public.

The information mechanism in this paper can be easily incorporated into macroeconomic models of larger scale. Therefore, the future research will consider the information problem at the zero lower bound in a medium scale DSGE model with a richer set of shocks and interactions across variables.

\section{SUPPLEMENTARY MATERIAL}

To view supplementary material for this article, please visit https://doi.org/10. $1017 /$ S1365100518001037

\section{NOTES}

1. In the presence of cheap talk [Crawford and Sobel (1982)], this information channel may be particularly important. Bassetto (2015) formally analyzes cheap talk in a macroeconomic setting.

2. Williams (2014) surveys monetary policy channels at the zero lower bound and policy instruments which have been put into practice.

3. Romer and Romer's (2000) conjecture is that this arises simply because the Fed devotes more resources to forecasting than the private sector.

4. See http://www.bbc.co.uk/news/business-26167707.

5. A more exhaustive list of justifications is provided in Section 2.2.

6. For instance, see Galí (2008).

7. See Hubert (2015) and Bassetto (2015).

8. For simplicity, this paper considers a logarithmic utility function for consumption.

9. The microfoundation for these equations can be found in standard reference books such as Walsh (2003), Woodford (2003), and Galí (2008).

10. For instance, see Clarida et al. (1999).

11. The demand shock is a function of total factor productivity [see Walsh (2003) and Galí (2008)] which the central bank should be able to assess more accurately than the private sector given the information advantage discussed in the introduction.

12. Alternatively, the information problem can be formulated with the assumption that the missing information in the private sector's information set is the current supply shock in the Phillips curve (2). In fact, the information value of the nominal interest rate and the associated information problem at the zero lower bound can be motivated around any unobservable that may enter the private sector block of the model. 
13. If the interest rate rule in (4) were forward-looking, the same reasoning goes through: in this case, the private sector uses the mappings from $E_{t} u_{t+1}=\rho u_{t}$, which is the conditional expected value of the demand shock, to the expected output gap $E_{t} x_{t+1}=\psi_{u}^{x} \rho u_{t}$ and the expected inflation $E_{t} \pi_{t+1}=$ $\psi_{u}^{\pi} \rho u_{t}$, and back out the current demand shock which takes the form $u_{t}=\hat{i}_{t} / \rho\left(\phi_{x} \psi_{u}^{x}+\phi_{\pi} \psi_{u}^{\pi}\right)$.

14. This belief may be wrong and still be model-consistent, which raises an important policy relevant issue that will be studied in this paper. The potentially wrong belief [which supports a misspecified equilibrium studied in the econometric learning literature; see Sargent (2001)] is due to the fact that (a) solving a model with an occasionally binding zero lower bound constraint requires a conjecture about the current (as well as the future) interest rate regime as an initial input (which needs to be validated in expectation; more on this in Section 3) and (b) this opens up the possibility that a zero lower bound period ensues in a self-fulfilling manner even when (7) is not true from the viewpoint of the central bank (which knows the true value of $u_{t}$ in $t$ ).

15. This formula is applicable because $\tilde{s}_{t}$ is entirely predetermined which allows it to be treated as a constant.

16. See Cameron and Trivedi (2005) for additional detail which includes the derivation of (10).

17. The specification of the interest rate rule is not essential for motivating and studying the information problem at the zero lower bound as long as the relationship between the nominal interest rate and the unobservables is linear. A promising alternative is the Wicksellian price level targeting rule $i_{t}=\psi_{p} p_{t}+\psi_{x} x_{t}$ where $p_{t}$ is the price level [see Bauducco and Caputo (2018)]. It has the advantage of achieving local determinacy in the monetary policy parameter region where the Taylor rule violates it. This paper adopts the Taylor rule so that its findings are more readily comparable to those in the literature, which are mostly concerned with the Taylor rule or its variants. I would like to thank an anonymous reviewer for pointing out this idea to me.

18. For notational simplicity, the conditional expectations operator $E_{t}$ is used to denote the expectations for both inside and outside the zero lower bound. Appendix B in the Supplementary Material contains more information about how the two expectations operators differ.

19. See Bodenstein et al. (2009) for the detail about the solution method.

20. There are alternative solution methods such as the cluster grid algorithm of Judd et al. (2011), the Smolyak collocation method of Fernández-Villaverde et al. (2015), and the shadow price shocks approach of Holden and Paetz (2012). Guerrieri and Iacoviello (2015) show that their solution method works as accurately as the dynamic programming method which can be taken to be virtually exact.

21. For instance, see Nakov (2008) where the effect of the zero lower bound on the nominal interest rate is explored in various settings which include optimal monetary policy under commitment and discretion and different specifications of interest rate rules.

22. The dynamics under smaller negative innovations to the demand shock are similar.

23. $\kappa=\frac{(\sigma+\eta)(1-\theta)(1-\beta \theta)}{\theta}$ for the basic new Keynesian model where $\sigma$ is the coefficient of relative risk aversion [see Walsh (2003)]. $\sigma=1$ given the logarithm utility function for consumption.

24. The mean paths of these variables are qualitatively similar.

25. For a recent treatment of this issue, see Basu and Bundick (2015).

26. For instance, see Christiano et al. (2015).

27. See Bloom (2014) and Jurado et al. (2015) for empirical evidence on how changes in uncertainty affect the economy and how recessions are associated with large increases in uncertainty.

28. Rewrite (1) and (2) using the forward substitution to see this.

29. See den Haan (2013) where views of various academic and policy economists are presented. The book volume indicates that macroeconomists have wide-ranging views about the efficacy of forward guidance.

30. Bassetto (2015) provides an example in which Delphic forward guidance is beneficial even when the announcement about the future policy is useless. This result depends crucially on the assumption that a central bank possesses superior information about the state of the economy (i.e., the potential level of output) than the private sector. For an overview of the literature which investigates sub-optimality of full transparency instead, see Cukierman (2009) and Gosselin et al. (2009).

31. It is straightforward to introduce noisy announcements to the model above. However, it only complicates the signal extraction rule without adding any further insight. 
32. For instance, see Gürkaynak et al. (2005).

33. See endnote 10 .

34. $\rho=\rho_{u}$ and $\sigma_{\varepsilon}=\sigma_{u}$. See Section 2.1.

35. Note that $\psi_{u}^{x}$ and $\psi_{u}^{\pi}$ here are distinct from those in equation (5).

36. The integrals in the coefficients above are computed using Gauss-Hermite quadrature with 30 sample points.

37. A wide array of values were tried for $\rho_{e}$ and $\sigma_{e}$. Simulation studies indicate that the higher the value of $\rho_{e}$ or $\sigma_{e}$, the longer the duration of a zero lower bound episode and the larger the size of output gap loss and deflation. The results are not included in the paper in the interest of space.

\section{REFERENCES}

Adam, K. and R. M. Billi (2007) Discretionary monetary policy and the zero lower bound on nominal interest rates. Journal of Monetary Economics 54(3), 728-752.

Alstadheim, R. (2016) The zero lower bound on the interest rate and a neoclassical Phillips curve. Journal of Macroeconomics 47(PA), 116-130.

Álvarez, L. J., E. Dhyne, M. Hoeberichts, C. Kwapil, H. Le Bihan, P. Lünnemann, F. Martins, R. Sabbatini, H. Stahl, P. Vermeulen and J. Vilmunen (2006) "Sticky prices in the Euro area: A summary of new micro-evidence. Journal of the European Economic Association 14(2-3), 575-584.

Aruoba, S. B. and F. Schorfeide (2012) Macroeconomic Dynamics Near the ZLB: A Tale of Two Equilibria. Working Paper.

Bassetto, M. (2015) Forward Guidance: Communication, Commitment, or Both? Society for Economic Dynamics, 2015 Meeting Papers: No. 216.

Basu, S. and B. Bundick (2015) Endogenous Volatility at the Zero Lower Bound: Implications for Stabilization Policy. Federal Reserve Bank of Kansas City, Research Working Paper RWP: No. 15-1.

Bauducco, S. and R. Caputo (2018) Wicksellian rules and the Taylor principle: Some practical implications. The Scandinavian Journal of Economics, first published on 03 October 2018.

Belgibayeva, A. and M. Horvath (2017) Real rigidities and optimal stabilization at the zero lower bound in new Keynesian economies. Macroeconomic Dynamics, first published on 22 June 2017.

Bianchi, F. and L. Melosi (2017) Escaping the great recession. American Economic Review 107(4), 1030-1058.

Billi, R. M. (2017) A note on nominal GDP targeting and the zero lower bound. Macroeconomic Dynamics 21(08), 2138-2157.

Blinder, A. S. (1998) Central Banking in Theory and Practice. Cambridge, MA: MIT Press.

Blinder, A. S., M. Ehrmann, M. Fratzscher, J. De Haan and D. Jansen (2008) Central bank communication and monetary policy: A survey of theory and evidence. Journal of Economic Literature 46(4), 910-945.

Bloom, N. (2014) Fluctuations in uncertainty. Journal of Economic Perspectives 28(2), 153-176.

Bodenstein, M., C. J. Erceg and L. Guerrieri (2009) The Effects of Foreign Shocks When Interest Rates are at Zero. Board of Governors of the Federal Reserve System (U.S.), International Finance Discussion Papers: No. 983.

Calvo, G. A. (1983) Staggered prices in a utility-maximizing framework. Journal of Monetary Economics 12(3), 383-398.

Cameron, A. C. and P. K. Trivedi (2005) Microeconometrics: Methods and Applications. Cambridge, UK: Cambridge University Press.

Campbell, J. R., C. L. Evans, J. D. M. Fisher and A. Justiniano (2012) Macroeconomic effects of federal reserve forward guidance. Brookings Papers on Economic Activity 44(1), 1-80.

Christiano, L. J., M. Eichenbaum and S. Rebelo (2011) When is the government spending multiplier large? Journal of Political Economy 119(1), 78-121.

Christiano, L. J., M. Eichenbaum and M. Trabandt (2015) Understanding the great recession. American Economic Journal: Macroeconomics 7(1), 110-167. 
Clarida, R., J. Galí and M. Gertler (1999) The science of monetary policy: A new Keynesian perspective. Journal of Economic Literature 37(4), 1661-1707, December.

Crawford, V. P. and J. Sobel (1982) Strategic information transmission. Econometrica 50(6), 1431-1451.

Cukierman, A. (2009) The limits of transparency. Economic Notes, Banca Monte dei Paschi di Siena SpA 38(1-2), 1-37.

den Haan, W. (2013) Introduction. In: W. den Haan (ed.), Forward Guidance: Perspectives from Central Bankers, Scholars, and Market Participants, A Vox-Eu.org eBook, Centre for Economic Policy Research. CEPR publication.

Eggertsson, G. B. and M. Woodford (2003) The zero bound on interest rates and optimal monetary policy. Brookings Papers on Economic Activity 34(1), 139-235.

Fernández-Villaverde, J., G. Gordon, P. Guerrón-Quintana and J. F. Rubio-Ramírez (2015) Nonlinear adventures at the zero lower bound. Journal of Economic Dynamics and Control 57(C), 182-204.

Flotho, S. (2015) Fiscal multipliers in a monetary union under the zero-lower-bound constraint. Macroeconomic Dynamics 19(06), 1171-1194.

Galí, J. (2008) Monetary Policy, Inflation, and the Business Cycle: An Introduction to the New Keynesian Framework. Princeton, NJ: The Princeton University Press.

Gosselin, P., A. Lotz and C. Wyplosz (2009) Interest rate signals and central bank transparency. NBER Chapters, In: NBER International Seminar on Macroeconomics 2007, National Bureau of Economic Research, Inc., pp. 9-51. NBER publication.

Guerrieri, L. and M. Iacoviello (2015) OccBin: A toolkit for solving dynamic models with occasionally binding constraints easily. Journal of Monetary Economics 70(c), 22-38.

Gürkaynak, R. S., B. Sack and E. Swanson (2005) Do actions speak louder than words? The response of asset prices to monetary policy actions and statements. International Journal of Central Banking 1(1), 55-93.

Hernandez-Murillo, R. and H. Shell (2014) The rising complexity of the FOMC statement," Economic Synopses, Federal Reserve Bank of St. Louis, issue 23.

Holden, T. and M. Paetz (2012) Efficient Simulation of DSGE Models with Inequality Constraints. School of Economics Discussion Papers: No. 1612, School of Economics, University of Surrey.

Hubert, P. (2015) Do central bank forecasts influence private agents? Forecasting performance vs. signals. Journal of Money, Credit, and Banking 47(4), 771-789.

Judd, K. L., L. Maliar and S. Maliar (2011) A Cluster-Grid Projection Method: Solving Problems with High Dimensionality. Working Paper.

Jung, T., Y. Teranishi and T. Watanabe (2005) Optimal monetary policy at the zero-interest-rate bound. Journal of Money, Credit, and Banking 37(5), 813-835.

Jurado, K., S. C. Ludvigson and S. Ng (2015) Measuring uncertainty. American Economic Review 105(3), 1177-1216.

Kuttner, K. N. (2001) Monetary policy surprises and interest rates: Evidence from the Fed funds futures market. Journal of Monetary Economics 47(3), 523-544.

Nakata, T. (2017) Uncertainty at the zero lower bound. American Economic Journal: Macroeconomics 9(3), 186-221.

Nakov, A. (2008) Optimal and simple monetary policy rules with zero floor on the nominal interest rate. International Journal of Central Banking 4(2), 73-127.

Ngo, P. (2018) The risk of hitting the zero lower bound and the optimal inflation target. Macroeconomic Dynamics 22(02), 402-425.

Pearlman, J., D. Currie and P. Levine (1986) Rational expectations models with partial information. Economic Modelling 3(2), 90-105.

Peek, J., E. S. Rosengren and G. M. B. Tootell (1999) Is bank supervision central to central banking? The Quarterly Journal of Economics 114(2), 629-653.

Romer, D. H. and C. D. Romer (2000) Federal reserve information and the behavior of interest rates. American Economic Review 90(3), 429-457. 
Rudebusch, G. D. and J. C. Williams (2008) Revealing the secrets of the temple: The value of publishing central bank interest rate projections. NBER Chapters, In: Asset Prices and Monetary Policy, National Bureau of Economic Research, Inc., pp. 247-289. NBER publication.

Sargent, T. J. (2001) The Conquest of American Inflation. Princeton, NJ: Princeton University Press. Sims, C. A. (2002) The role of models and probabilities in the monetary policy process. Brookings Papers on Economic Activity33(2), 1-62.

Walsh, C. E. (2003) Monetary Theory and Policy, 2nd ed. Cambridge, MA: MIT Press Books, MIT Press.

Werning, I. (2012) Managing a Liquidity Trap: Monetary and Fiscal Policy. MIT, Working Paper.

Williams, J. C. (2014) Monetary policy at the zero lower bound: Putting theory into practice. Hutchins Center on Fiscal and Monetary Policy at Brookings.

Woodford, M. (2003) Interest and Prices: Foundations of a Theory of Monetary Policy. Princeton, NJ: The Princeton University Press.

Woodford, M. (2005) Central bank communication and policy effectiveness. In: Proceedings Economic Policy Symposium - Jackson Hole, Federal Reserve Bank of Kansas City, pp. 399-474.

Woodford, M. (2011) Simple analytics of the government expenditure multiplier. American Economic Journal: Macroeconomics 3(1), 1-35.

Wu, J. C. and F. D. Xia (2016) Measuring the macroeconomic impact of monetary policy at the zero lower bound. Journal of Money, Credit and Banking 48(2-3), 253-291. 